
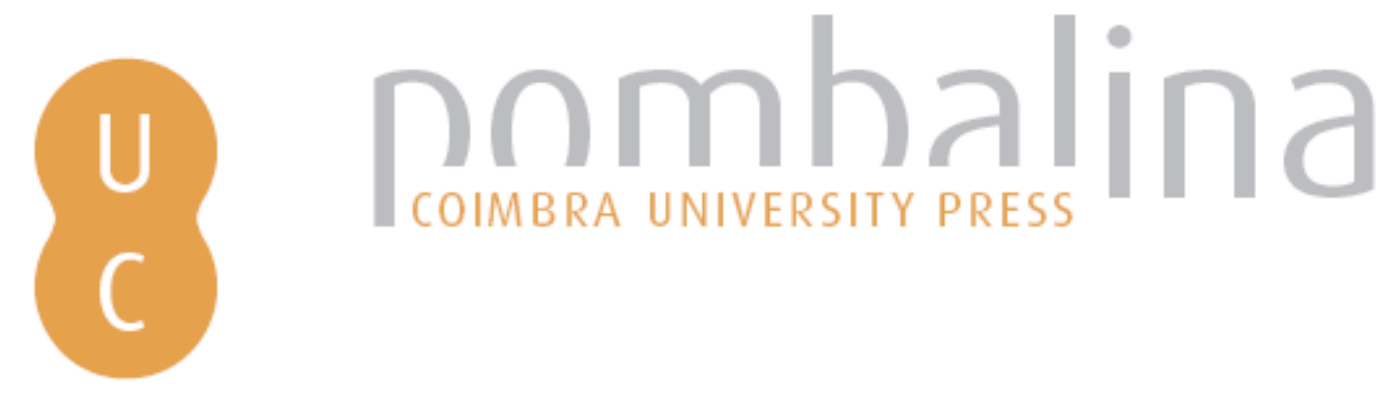

\title{
Construção da verdade autoritária: palavras, imagens e propaganda da Era Vargas em Pernambuco (19301945)
}

Autor(es): $\quad$ Almeida, Maria das Graças Andrade Ataide de

Publicado por: Imprensa da Universidade de Coimbra

URL

persistente: URI:http://hdl.handle.net/10316.2/39000

DOI: $\quad$ DOI:http://dx.doi.org/10.14195/978-989-26-1064-1_6

Accessed : $\quad$ 26-Apr-2023 13:58:58

A navegação consulta e descarregamento dos títulos inseridos nas Bibliotecas Digitais UC Digitalis, UC Pombalina e UC Impactum, pressupõem a aceitação plena e sem reservas dos Termos e Condições de Uso destas Bibliotecas Digitais, disponíveis em https://digitalis.uc.pt/pt-pt/termos.

Conforme exposto nos referidos Termos e Condições de Uso, o descarregamento de títulos de acesso restrito requer uma licença válida de autorização devendo o utilizador aceder ao(s) documento(s) a partir de um endereço de IP da instituição detentora da supramencionada licença.

Ao utilizador é apenas permitido o descarregamento para uso pessoal, pelo que o emprego do(s) título(s) descarregado(s) para outro fim, designadamente comercial, carece de autorização do respetivo autor ou editor da obra.

Na medida em que todas as obras da UC Digitalis se encontram protegidas pelo Código do Direito de Autor e Direitos Conexos e demais legislação aplicável, toda a cópia, parcial ou total, deste documento, nos casos em que é legalmente admitida, deverá conter ou fazer-se acompanhar por este aviso.

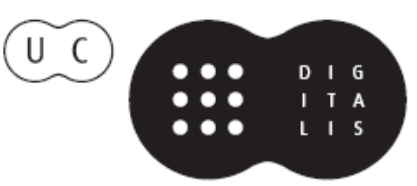


A L B ERTO PENA-RODR ÍGUEZ HELOISA PAULO

COOR D.

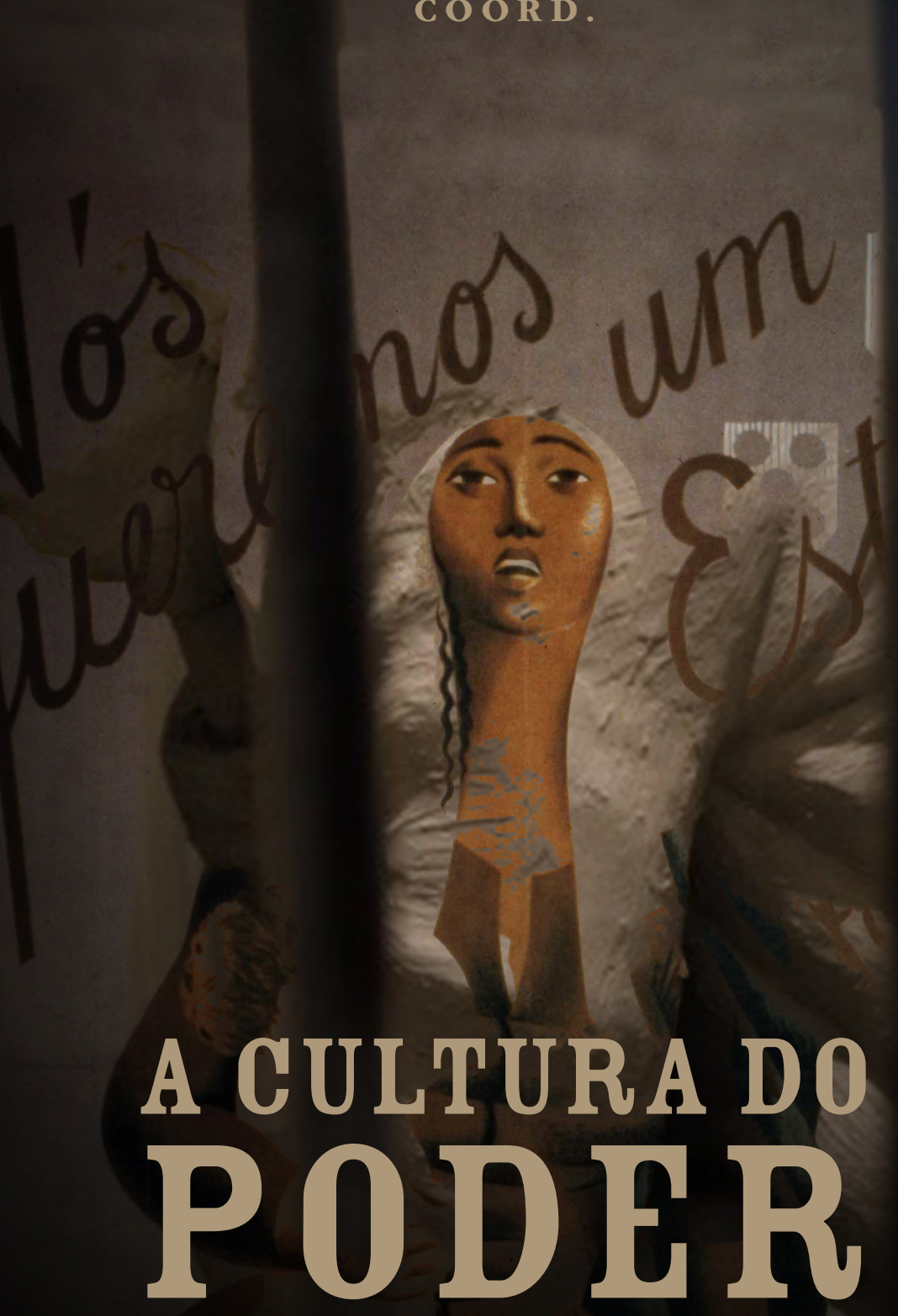

A PROPAGANDA INOS ESTADOS AUTORITÁRIOS 


\section{CONSTRUÇÃO DA VERDADE AUTORITÁRIA : PALAVRAS, IMAGENS E PROPAGANDA} DA ERA VARGAS EM PERNAMBUCO (1930-1945)

Maria das Graças Andrade Ataide de Almeida

A Interventoria Agamenon Magalhães em Pernambuco - 1937 a 1945 - foi apontada como modelo a ser seguido em todo o Brasil. A argumentação era construída num discurso que afirmava a sintonia da interventoria com o ideário estadonovista: a transformação do espaço público seguindo parâmetros autoritários e excludentes, apontando para uma eleição dos marginalizados e indesejáveis, construindo a imagem do outro indesejável, tanto por sua raça como pela ideologia; a reificação da imprensa como veículo de doutrinamento político; o uso da educação como veículo ideológico ${ }^{1}$ e por fim o pacto com a Igreja como sustentáculo e corolário da nova ordem vigente.

A Igreja Católica por sua vez teve a percepção do momento de crise que o Estado atravessava, e investiu neste flanco aberto, numa produção de um discurso maniqueísta apontando a impossibilidade de qualquer Poder civil ter legitimidade e se manter sem uma relação direta com o apoio da Igreja. Pierre Bourdieu ${ }^{2}$

\footnotetext{
1 APLLE, M. Currículo e poder. Porto Alegre: 2008

2 BOURDIEU, Pierre. A Economia das trocas simbólicas. SP: Perspectiva, 1989.
} 
em seu trabalho A Economia das Trocas Simbólicas, aponta a relevância do discurso profético em períodos de crise da sociedade, uma vez que este momento de crise dá subsídios à Instituição de oferecer a instrumentalidade que possui nos seus sistemas simbólicos. O fio condutor do discurso construído pela Igreja naquele momento se voltava para apontar a degeneração moral e ética que havia-se instaurado no Brasil com a República. As marcas do discurso profético apontava para um país que deveria retroceder a uma era de ouro, ${ }^{3}$ perdida, e fazer uma nova trajetória, onde a tradição, a moral, a fé e a ordem trariam segurança e paz à nação. Este discurso profético da Igreja em Pernambuco, no Estado Novo, trabalhava com o interdiscurso - uma memória discursiva- ${ }^{4}$ do medo do comunismo, prometendo construir uma elite fiel, envolvida nos cargos políticos, voltada para a erradicação do comunismo e ao crescimento da fé católica, antídoto contra o credo de Moscou.

A imprensa, tendo como porta voz da interventoria o jornal Folha da Manhã - criado para tal fim- se constitui como o "quarto poder" na propagação e disseminação do ideário autoritário estanovista, assim como também os jornais e revistas católicas5.

Entender a construção deste paradigma que se instaura no Brasil em 1937, é possível através da desconstrução da produção de discurso do Poder político, da instrumentalidade da propaganda, e do entendimento das imbricações entre este discurso e o discurso da Igreja, onde as marcas do discurso do sagrado e do político se

3 GIRARDET, R. Mitos e mitologias politicas. SP: Cia. Das Letras, 1987

${ }^{4}$ ORLANDI, E. Análise de discurso. Campinas/SP: Pontes, 1995

5 Os jornais A Tribuna (porta voz da Cúria metropolitana de Recife e Olinda; A Gazeta, porta voz da importante paróquia da Boa Vista. A revista Maria, porta-voz da Congregação Mariana em Pernambuco, representa um excelente acervo do uso da imprensa na construção de uma ideologia autoritária e conservadora da congregação entre os jovens intelectuais do estado. Destacamos o número de novembro de 1935. 
imbricam. Esta produção de discurso aponta para a sacralização das instituições e da instrumentalidade do laicato católico, onde estes intelectuais estão ao serviço da construção de visões de mundo no Estado autoritário.

A imprensa, eleita pela Interventoria como veículo qualificado para o doutrinamento da sociedade, reificou o papel do jornalista que, naquele contexto, extrapolou a função profissional, metamorfoseado na trilogia político/intelectual/jornalista. Nesta ótica, o grupo de colaboradores do jornal, a Fôlha da Manhã, porta-voz da Interventoria, representou em sua maioria, o laicato católico, os intelectuais de Pernambuco e o staff político do Estado. O que ressaltamos aqui é o fato desses jornalistas/católicos, intelectuais egressos da Faculdade de Direito de Recife, ao serem cooptados para os cargos políticos do Estado, terem assumido com lealdade e fidelidade as atividades de veiculadores das "visões de mundo" de um governo que elegeu, como via para garantir seu "exemplo de interventoria", o autoritarismo, a excludência e o racismo: cânones presentes nos modelos nazi-fasci europeus.

Foi possível entender como a Igreja conseguiu tal preeminência em Pernambuco somente a partir da compreensão do processo de reificação da instrumentalidade do papel da elite católica que, cooptada pela Interventoria, pôde ser utilizada para equacionar os medos e os perigos eleitos pelo Estado autoritário como nocivos à sociedade. Neste sentido, este grupo de intelectuais assimilou o ideário autoritário daquela conjuntura, elegendo a cidade do Recife como espaço a ser higienizado e transformado, em que o autoritarismo impunha um controle sobre a população em seus aspectos mais inusitados. Modernidade e progresso foram categorias apontadas como imprescindíveis para a transformação do espaço e do cotidiano urbano de seus moradores.

Buscava-se, através das reportagens e fotografias veiculadas pela imprensa oficial, dar uma identidade cultural à cidade. A fotografia 
presta-se a isso, pois favorece a manipulação da realidade ${ }^{6}$ : omite-se, elimina-se o que não se quer mostrar; daí a imagem oficial. Neste sentido, a verdade autoritária foi construída onde os conceitos de bem e mal se polarizavam, elegendo os sãos e perseguindo os inoculados pelas idéias exóticas importadas.

Uma produção de discurso veiculada pela imprensa, trazia as marcas do discurso dos regimes fascistas europeus, em que o nacionalismo e o anti-semitismo emergem como cânones do paradigma autoritário. As idéias importadas dos "modernos" países europeus desempenharam um importante papel na construção de um discurso autoritário, que marca um interdiscurso presente no Brasil e que, nos momentos de crise econômica e instabilidade política, aponta caminhos para a implantação de modelos onde o autoritarismo torna-se a solução para o equacionamento dos problemas nacionais.

A imprensa brasileira da Era Vargas transformou-se em instrumento da reprodução da infâmia sustentada pelo ideário racista, vigente em alguns países europeus. É difícil equacionar ao certo o poder de alcance das matérias que circularam pela imprensa de Pernambuco. O jornal Folha da Manhã era lido por, no mínimo quinze mil leitores diários, disseminando a crença de que a exclusão do imigrante judeu livraria o país dos "maus elementos". Este discurso construiu uma verdade autoritária onde as palavras, imagens e propaganda permitiram que um anti-semitismo virulento apontasse o judeu como o "outro maléfico", diabolizado, alimentando e permeando o imaginário social em Pernambuco. ${ }^{7}$

A América do Norte representava a influência da ideologia liberal que desencadeava a desordem, a velha Europa católica apontava para a reintegraçao da ordem, através da ideologia nacionalista e autoritária dos regimes nazi-fasci. Um discurso diário veiculado

\footnotetext{
${ }^{6}$ KOSSOY, B. Fotografia e História. SP: Ática, 1989

7 BAZCKO, B. Los Imaginarios sociales. Buenos Aires: Paidós,2007
} 
pela imprensa fazia apologia à Itália, a Portugal, à Espanha, e à Alemanha, como países que haviam conseguido vencer o caos através de governos fortes e autoritários.

O uso da propaganda fascista como solução para os problemas do Brasil, era associado ao catolicismo. A produção do discurso dos intelectuais, como Lacerda de Almeida ${ }^{8}$ entre outros, em livros e artigos apontava que seria o fascismo o expurgador e reformador da Itália com base num trabalho do verdadeiro "genio latino, que é cathólico, e na instituição maxima italiana o catholicismo." O discurso da Igreja apontava o fascismo como o paradigma que poderia de restaurar o poder católico e conseqüentemente imprimir a ordem social:

"o fascismo que não receiou de ser chamado reaccionario [...] ILLIBERAL e ANTI-LIBERAL.O fascismo não conhece ídolos, não adora fetiches; passou elle já e, se fór necessário, tornará a passar ainda, com serenidade sobre o corpo mais ou menos putrefacto da deusa Liberdade" 9 .

Elias Canetti ${ }^{10}$, trabalhando as relações do uso da massa pelo poder, aponta a preocupação da Igreja em usar o que ele conceitua de massa aberta (onde não há controle) e criar condições do uso da massa fechada, onde os limites garantem a hierarquia e o controle, a exemplo das procissões, em que esta hierarquia é bem delimitada, ou nos recintos fechados dos cultos. Para Canetti, em raros momentos a Igreja deixa de agir assim e utiliza a massa

8 AlmeIDA, L. de. A Igreja e o Estado. RJ: Typografia Revista dos Tribunais, 1924.

9 ALMEIDA, L. de. A Igreja e o Estado. RJ: Typografia Revista dos Tribunais, 1924, pp. VIII e VII.

10 CANETTI, E. Massa e poder. Massa e Poder. Brasilia:UNB;SP:Melhoramentos, 1983. 
aberta, a exemplo do movimento das cruzadas: "o exemplo mais grandioso de uma deliberação de massas realizada pela Igreja são as cruzadas"11. No Brasil e em especial em Pernambuco, através do Interventor Agamenom Magalhães, este ideário cruzadista, nos anos 30, se utilizou de três frentes de ação: a Cruzada de Educadoras Católicas, a Ação Católica e a Liga Eleitoral Católica. Todos três utilizando o espaço da imprensa como instrumento de propaganda e disseminação do ideário autoritário.

Em 1935, em Pernambuco, o levante comunista levou a Igreja a empreender uma acirrada campanha anti-comunista, com um discurso em que os comunistas estariam dominando os cargos públicos e especialmente, os da área da educação, transformando o estado em uma nova Rússia. Seis meses após, as notícias veiculadas pela imprensa nacional sobre a Guerra Civil Espanhola (1936/1939), corroboravam este discurso, alimentando o imaginário político dos anos trinta. ${ }^{12}$ A imprensa católica veiculava textos virulentos sobre os revolucionários, reproduzindo fotos de igrejas espanholas invadidas, com seus utensílios sagrados, "profanados pelos ateus comunistas"13.

Este contexto inspirou a Igreja, no ano seguinte, a empreender uma campanha fundamentada na imposição de um dos mais marcantes símbolos do catolicismo: a exposição pública do crucifixo em todas as escola do Estado, salvaguardando o imaginário das tradições do catolicismo. A Igreja apregoava sob esta ótica, em manchetes bombásticas, que as normalistas de Pernambuco exigiam a recristianização da escola ${ }^{14}$.

11 CANETTI, E. Massa e Poder. Brasilia:UNB;SP:Melhoramentos, 1983, pp. 173-174 .

12 Ver os artigos da Revista Maria; ver também CARNEIRO, Maria Luiza Tucci. La Guerra Civil Española através de lãs revistas ilustradas brasileñas:imagens y simbolismo. In Estudios Interdisciplinares de America Latina e Caribe, (2),v.2,Julio/deciembre de 1991, pp. 50-59.

13 A Tribuna, Recife, 27/01/1934, p. 1.

${ }^{14}$ A Tribuna, Recife, 21/05/1936, pp. 1 e 3 
Nas formas de produção do discurso ${ }^{15} \mathrm{em}$ que as normalistas exigem a recristianização das escolas, percebe-se o discurso dos componentes da Cruzada de Educadoras Católicas contra o comunismo. Repetindo o discurso veiculado pela imprensa religiosa acerca dos supostos estupros infringidos às mulheres, leigas e religiosas, pelos comunistas no México, as normalistas se posicionavam como defensoras da honra da mulher brasileira, apontada como o "penhor sagrado da inviolabilidade dos nossos lares" ${ }^{\prime 6}$. Concluem a petição referindo-se ao movimento de novembro de 1935, como uma grande ameaça, similar àquela representada pela invasão holandesa de 1580. Recuperando a epopéia desempenhada pelas mulheres pernambucanas em Tejucupapo, frente ao invasor infiel, o holandês, comparam-no aos comunistas, que também colocavam em perigo a pátria e a família:

"[...] considerando que os inimigos da pátria e da família, infiltrando-se pelas camadas sociaes, derramaram o sangue dos nossos irmãos e ameaçam ainda os fundamentos da soberania nacional, os corações das jovens pernambucanas palpitam sob o mesmo rytmo que activou as heroínas deTejucupapo contra o invasor sanguinário". ${ }^{17}$

O Estado endossava o pedido das futuras mestras. Em ofício datado de 20 de maio de 1936, a Igreja justificava ao Secretário do Interior, a importância de afixar o crucifixo nas escolas, ressaltando numa linguagem carregada de simbolismos, que o crucifixo representava a fé e a redenção do Brasil. Louvava também a atitude de

\footnotetext{
15 ORLANDI, E. Análise de discurso. Campinas/SP: Pontes, 1995.

16 Revista Maria, Recife, 1936, pp. 146-147.

17 Revista Maria, Recife, 1936, pp. 146-147..
} 
manifestação de civismo das estudantes, apontada como um contraste na conjuntura por que passava Pernambuco:

"[...] quando a horda nefasta de mercenarios vis se levanta cheia de ódios propagando idéas que corrompem os costumes, extinguem os dogmas christãos[..] destrõem a família e aviltam a pátria" 18 .

Dois meses antes uma lei salazarista obrigava o uso do crucifixo em todas as escolas portuguesas. O jornal A Gazeta, chegou a elogiar a atitude da Camara Corporativa Portuguesa, que estava cuidando de proporcionar um plano de educação, em que não houvesse uma brecha favorável á infiltração das teorias "anárquicas", que estivesse expurgado da obra tida como infernal e criminosa dos agentes da Terceira Internacional e, finalmente que contasse com uma propaganda nacionalista e ordeira, oposta à preparada pelo "bureau da propaganda communista, montado em repartições especiaes da Russia"19.

José Murilo de Carvalho, ao analisar a construção do imaginário social na primeira República comparando-o com o da Revolução Francesa, observa a relevância da proposta de se edificar uma imagem do novo regime, construindo-o nos moldes do regime emergente. ${ }^{20}$

O pacto entre Igreja e Estado concretizou-se sob a forma de uma nova "ordem simbólica", cristã, que tinha como o objetivo legitimar o novo regime junto às massas. ${ }^{21}$ Esta teoria fica clara na relevância

\footnotetext{
18 Revista Maria, Recife, 1936, p. 146.

19 Revista Maria, Recife, 1936, p. 146.

20 CARVAlHO, J. Murilo. A formação das almas: o imaginário da república no Brasil. SP: Cia das Letras, 1990.

$21 \mathrm{O}$ uso da liturgia católica na formação da ordem simbólica é muito relevante para se apreender a força simbólica que a Igreja manuseava muito bem para cooptar
} 
que é dada ao papel da liturgia na Igreja Católica no período em questão. Sua importância na vida do laicado católico, ligado à elite política dominante do Estado, instituia-se não só na obrigatoriedade da freqüência à missa e à eucaristia, como também na pregação constante e persuasiva de que o centro das associações católicas girava em torno da mesa da comunhão. Para aquela instituição, todas as questões fossem elas políticas ou sindicais, seriam resolvidas na mesa eucarística, em que não havia divisão de classes. Esta mesa reunia e dissolvia os conflitos que pudessem existir entre o milionário e o miserável; o cientista e o ignorante. À eucaristia imputava-se o sacramento do trabalho, da igualdade, do amor. Através dela o mundo seria perfeito e a justiça realizada. As revoltas se extinguiriam e ninguém mais morreria de fome. A Igreja trabalhava de forma maniqueísta o oposto dessa relação, apontando para o "plano" comunista, que consistia em acirrar o ódio entre patrões e empregados, incentivando a luta de classes, para "o aniquilamento da Pátria, vendendo-a ao capitalismo judaico da Rússia”. Assim, ela acenava com o consenso social via ordem simbólica ${ }^{22}$.

Em 1939, ao ser instituído o Ano Litúrgico, as Pastorais passaram a ressaltar o papel da liturgia como elo de união entre os católicos. O III Congresso Eucarístico Nacional, realizado em Recife em setembro de 1939, tinha como um dos seus lemas que o catolicismo militante dependeria do praticante. E afirmava que seria inútil qualquer trabalho, superficiais todas as organizações, se tudo isto

\footnotetext{
os segmentos sociais para as suas fileiras. Ver também: SOUZA, JOSE FERREIRA. “A Eucaristia e a Questão Social”. In: A Ordem, julho, 1938, p 24-26; acerca do ANO LITÚRGICO (1939), vide artigo de Fábio A. Ribeiro, "O Ano Litúrgico", In: Ação Católica, janeiro, 1939, p 16-17; vide também - BOURDIEU, Pierre. A Economia das trocas simbólicas. São Paulo: Perspectiva, 1987

22 Ver: PIO XII, ENCICLICA "DIVINI REDEMPTORIS",1937. Rio de Janeiro, Editora A.B.C. Limitada. Esta Encíclica, conhecida como "Sôbre o Comunismo Ateu", evidencia a preocupação de Roma com o catolicismo nas Américas; ver também Revista Maria; Sôbre o Papa Pio XI ver: KIRBY, Edvard. Pio XI o Apóstolo da Paz. S. Paulo: Ed. Panamericana, 1945.
} 
não estivesse relacionado com o sacramento diário da missa e da eucaristia. ${ }^{23}$

A Carta do Episcopado Brasileiro, de 9 de junho de 1935, instituiu oficialmente a Ação Católica, espalhada em grupos por todo o país. O texto do documento é suscinto: dois parágrafos acerca dos objetivos do novo veículo catequético da Igreja, ressaltando os desejos paternais e os elevados propósitos de Pio XI em organizar a Ação Católica em todo o mundo, para a salvação das almas e da Pátria. ${ }^{24}$

Entender o papel do laicato católico no contexto em questão, não só a nível regional, nacional como a nível internacional, é apreender a instrumentalidade do mesmo, como único veículo percebido pela Igreja para resgatar o seu poder político junto ao Estado. Recatolizar as mentes, e poder interferir no palco político decisório das nações fazia com que o laicato se tornasse a menina dos olbos do Papa Pio XI, não só na Encíclica Ubi Arcano Dei, em 1922, criando a Ação Católica, mas em todas as outras Encíclicas subsequentes. A base do discurso do Pontífice sustentava-se na importância dada ao trabalho desses leigos junto aos vários segmentos sociais, fiéis à doutrina de Roma.

Assim a Ação Católica passou a ser revitalizada no mundo inteiro pela Encíclica Ubi Arcano Dei, com o objetivo de recristianizar o mundo em crise através do laicato fiel. A Ação Católica, trabalhando em conjunto com o clero, desempenhou um papel importantíssimo para a recuperação do espaço junto ao poder político. A percepção

23 LEME, Sebastião de Cintra. Discurso proferido quando do encerramento dos trabalhos do III Congresso Eucaristico Nacional em Recife, 3 a 7 de setembro de 1939. In: Annaes do III Congresso Eucharistico Nacional. Recife: Officinas Graphicas do Jornal do Commercio, 1940, p 351-353

24 A literatura produzida na época acerca da importância do laicato no soerguimento e irradiação da fé católica é exaustiva. As ENCÍCLICAS de Pio XI, especialmente a UBI ARCANO DEI (1922) e a QUADRAGÉSIMO ANNO, (1931) trazem como tema prioritário a cooptação de uma elite laica em todos os paises católicos, com a função de infiltrar esta elite junto ao Poder político. 
do Papa Pio XI ao usar uma elite doutrinando-a na obediência fiel aos canônes da Igreja Romana e inferindo-a nos postos chaves da política nacional, garantiria à Igreja não somente resgatar o poder político, mas também a sua própria linha de continuidade. Por esta razão a Instituição justificava a necessidade de ter intelectuais ligados ao clero, esclarecendo a impenetrabilidade de certos ambientes ao ministério do sacerdote.

A Revista Para o Alto, porta-voz das lideranças católicas, - Juventude Operária Católica (JOC) e Juventude Estudantil Católica (JEC) - expressava em seu discurso esta elitização da Ação Católica. Seus artigos sobre a Juventude Operária Católica construíam sempre a imagem do trabalhador sob a égide da Ação Católica: religioso, conformado, ordeiro, pacífico. Essa elitização da liderança na Ação Católica, proposta por Pio XI é sempre justificada pelo clero e por intelectuais católicos. Alceu Amoroso Lima foi neste contexto, um dos defensores da idéia de se efetivar a relação cultural das elites eliminando os incapazes:

"dia a dia se mostram as massas mais incapazes de trazer ao mundo a paz e a prosperidade. O século XIX foi o século da alfabetização das massas. o século XX será o da seleção cultural das elites". 25

O alcance da propaganda atingia a leitura a ser utilizada A revista Ação Católica, porta-voz da Ação Católica Brasileira, assumiu a divulgação do movimento fazendo intercâmbio a nível nacional e internacional. Utilizando-se de múltiplos subterfúgios, como por exemplo: trazer uma secção de análise de livros e filmes que poderiam ou não ser lidos ou vistos pelos fiéis; apontava também a clientela que deveria ser cooptada para servir naquele apostolado,

25 LIMA, Alceu Amoroso. Revista A Ordem, 1934, p. 69. 
justificando que nem todos os fiéis poderiam prestar esta colaboração. Afirmava que só uma elite, a qual estaria sempre em minoria, poderia fazer oposição ao mal.

O tratamento do discurso acerca do estado e o mal do comunismo. Interessante observar que o Estado era tratado, simbolicamente, como um corpo doente, infectado. O comunismo e o liberalismo eram apresentados como um mal a ser extirpado, tese já defendida por alguns historiadores brasileiros. A nação estava doente, assim como a escola primária estava poluída de docentes infectados pelas idéias bolchevistas:

"o expurgo deve abranger o ensino primário e certamenete com maior severidade que nas escolas secundárias e superiores. A escola primária está polluída por muitos professores e professoras infectados pela demagogia comunista". ${ }^{26}$

A Igreja apontava, convicta, as manifestações da doença: "membros gangrenados". A educação era portanto a única possibilidade de profilaxia. Daí a solução apresentada ser expressa numa linguagem violenta e excludente:

"a ablação desses membros granguenados, deveria ser feito com cirurgia urgente e sem a contemporização dos anesthesicos". ${ }^{27}$

O Estado aceitou o pacto. As vozes dos poderes temporal e espiritual eram uníssonas contra os bolchevistas. Erradicar esses "infectados, gangrenados", do corpo sadio da sociedade civil, era portanto alvo da Interventoria Agamenon Magalhães, enquanto que monopolizar a educação era explicitado pela Igreja como possibi-

26 "Medida Incompleta", In: A Gazeta, Recife, 18.10.1937, p. 1.

27 "Medida Incompleta", In: A Gazeta, Recife, 18.10.1937, p. 1. 
lidade dela dominar o mundo de amanhã. Seu discurso apoiava-se sempre no ideal de formar gerações fiéis ao catolicismo que garantissem a preeminência da filosofia Católica Romana na futura elite dominante, geração esta que não permitiria dominassem o país tipos como o "judeu Calles" apontado como trucidador de cristãos no México. A imprensa religiosa e laica, afirmava que a escola mexicana era "visceralmente athéa e bolchevista" 2 .

28 Revista Maria, Recife, agosto/setembro 1936, pp. 213-214. 